Arq. Bras. Med. Vet. Zootec., v.66, n.3, p.818-826, 2014

\title{
Padrões de deslocamento de bezerras de corte que receberam suplementos isolipídicos em pastagem de azevém
}

\author{
[Displacement patterns of beef heifers receiving iso lipidic supplements on ryegrass pasture] \\ M.J.O. Sichonany ${ }^{1}$, M.G. Rocha ${ }^{2}$, L. Pötter ${ }^{2}$, A.T.N. Rosa ${ }^{1}$, C.L. Glienke ${ }^{1}$, \\ L.A. Ribeiro ${ }^{1}$, L.R. Eloy ${ }^{1}$, V.S. Hampel ${ }^{1}$ \\ ${ }^{1}$ Aluno de pós-graduação - UFSM - Santa Maria, RS \\ ${ }^{2}$ Universidade Federal de Santa Maria - UFSM - Santa Maria, RS
}

\section{RESUMO}

Foram avaliados o uso de estações alimentares, o deslocamento e a taxa de bocado de bezerras de corte que foram mantidas exclusivamente em pastagem de azevém (Lolium multiflorum Lam.) ou receberam suplementos (grão de milho ou gordura). O método de pastejo foi contínuo, com número variável de animais. O delineamento experimental foi inteiramente ao acaso, com medidas repetidas no tempo. O número de bocados realizados por estação alimentar é similar quando as bezerras recebem suplemento ou não. As equações de predição mostram que a massa de lâminas foliares exerce maior influência no tempo por estação alimentar quando as bezerras permanecem exclusivamente em pastejo de azevém ou recebem grão de milho como suplemento, enquanto para bezerras que recebem gordura, essa variável é influenciada pela oferta de forragem. O deslocamento (passos entre estações e passos por minuto) de bezerras exclusivamente em pastejo e que recebem grão de milho é influenciado pela estrutura e qualidade do pasto. A taxa de bocado dos animais suplementados com grão de milho e gordura é influenciada pela proporção de lâminas foliares no dossel. Equações de regressão múltipla, considerandose os atributos do pasto e da pastagem, podem ser utilizadas como modelos preditores do uso de estações alimentares, deslocamento e taxa de bocado de bezerras de corte.

Palavras-chave: estações alimentares, grão de milho, gordura, Lolium multiflorum

\begin{abstract}
The use of feeding stations, displacement patterns and bite rate of beef heifers kept exclusively on Italian ryegrass (Lolium multiflorum Lam) or receiving supplements (corn grain or fat) were evaluated. The grazing method was continuous with a variable number of animals. The experimental design was a completely randomized design with repeated time measures. The number of bites per feeding station is similar when heifers receive supplement or not. The prediction equations show that the mass of leaf lamina has greater influence on the time per feeding station when heifers remain exclusively grazing ryegrass or receive corn grain as a supplement, while for calves that receive fat this variable is influenced by forage allowance. The displacement (steps between stations and steps per minute) of heifers exclusively on ryegrass or receiving corn grain is influenced by the structure and quality of grass. The bite rate of heifers supplemented with corn grain and fat is influenced by the proportion of leaf lamina in the sward. Multiple regression equations considering the attributes of grass and pasture can be used as models to predict the use of feeding stations, displacement and bite rate of beef heifers.
\end{abstract}

Key words: continuous grazing, fat, feeding stations, Lolium multiflorum, seed corn

Recebido em 2 de outubro de 2012

Aceito em 7 de novembro de 2013

E-mail: maria_sichonany@hotmail.com 


\section{INTRODUÇÃO}

O conhecimento do comportamento ingestivo dos herbívoros é uma ferramenta importante no manejo de pastagens, pois o animal responde às características do seu ambiente pastoril, com relação à quantidade e à qualidade do alimento fornecido. Podem-se, assim, identificar condições de manejo adequadas à categoria animal e ao sistema de produção adotado, visando à sua maior eficiência. A produção animal em pastagem depende de fatores relacionados à planta, ao animal e ao suplemento concentrado fornecido.

O azevém (Lolium multiflorum Lam.) é a mais importante opção forrageira no Rio Grande do Sul, pois permite manter uma oferta permanente de alimento em quantidade e qualidade em um período de pouca produção da pastagem natural. $\mathrm{O}$ fornecimento de suplementos energéticos para bezerras em pastejo em azevém tem por finalidade antecipar a sua puberdade, de forma a assegurar o ganho de peso desejado para o seu desenvolvimento adequado, permitindo o seu acasalamento aos 14 ou 18 meses de idade.

O grão de milho está entre os concentrados energéticos mais utilizados para animais em pastejo, proporcionando ganhos de $0,968 \mathrm{~kg} \mathrm{dia}^{-1}$ (Santos et al., 2005). O interesse no fornecimento de gordura aos ruminantes tem aumentado, pois seu uso apresenta efeitos desejáveis, tais como inibição da produção de metano, redução da concentração de amônia ruminal e aumento na eficiência da síntese microbiana (Lin et al., 1995).

A quantidade e o tipo de suplemento podem determinar diferentes respostas no comportamento ingestivo e nos padrões de deslocamento dos animais ao longo das estações alimentares, onde cada sequência de apreensão ou alimentação é realizada. Os animais que recebem suplementos tendem a reduzir o tempo de pastejo em relação aos exclusivamente em pastejo, bem como a diminuir o número de estações alimentares, o tempo de permanência em cada estação alimentar e o seu deslocamento (Glienke et al., 2010).

O entendimento do processo de seleção das áreas para a realização do pastejo pode facilitar a compreensão dos efeitos do uso de diferentes suplementos e também do efeito da estrutura da forrageira hibernal no comportamento ingestivo de novilhas de corte. Este trabalho foi realizado com o objetivo de avaliar o uso de estações alimentares, o deslocamento e a taxa de bocado de bezerras de corte que foram mantidas em pastagem de azevém e receberam grão de milho ou produto comercial extrusado com gordura como suplemento e, assim, relacioná-los com os atributos estruturais do dossel forrageiro e a composição química da forragem aparentemente consumida.

\section{MATERIAL E MÉTODOS}

O experimento foi realizado no Departamento de Zootecnia da Universidade Federal de Santa Maria (UFSM), Rio Grande do Sul, no período de julho a outubro de 2009. O solo da área experimental é classificado como argissolo vermelho distrófico arênico. A região possui clima subtropical úmido (Cfa), conforme classificação de Köppen.

Os dados meteorológicos referentes aos meses que compreenderam o período experimental foram obtidos junto à Estação Meteorológica da Universidade Federal de Santa Maria (Tab. 1).

Tabela 1. Valores médios de temperaturas máxima, mínima, média e precipitação pluviométrica

\begin{tabular}{|c|c|c|c|c|}
\hline \multirow{2}{*}{ Item } & \multicolumn{4}{|c|}{ Meses } \\
\hline & Julho & Agosto & Setembro & Outubro \\
\hline \multicolumn{5}{|l|}{ Médias observadas } \\
\hline Temperatura média $\left({ }^{\circ} \mathrm{C}\right)$ & 10,5 & 16,2 & 15,7 & 18,4 \\
\hline Precipitação pluviométrica $(\mathrm{mm})^{1}$ & 102,2 & 179,8 & 368,4 & 109,2 \\
\hline \multicolumn{5}{|l|}{ Médias históricas } \\
\hline Temperatura média $\left({ }^{\circ} \mathrm{C}\right)^{1}$ & 13,5 & 14,6 & 16,2 & 18,8 \\
\hline Precipitação pluviométrica $(\mathrm{mm})^{1}$ & 145,6 & 137,4 & 153,6 & 145,9 \\
\hline
\end{tabular}


A área experimental foi constituída de 4,9ha, dividida em seis piquetes, e mais uma área contígua de 1,5ha. Para formar a pastagem de azevém (Lolium multiflorum Lam.), foi realizado preparo mínimo do solo e semeadura a lanço de 40kg ha ${ }^{-1}$ de sementes em 17 de maio. A adubação constou de $200 \mathrm{~kg} \mathrm{ha}^{-1}$ de NPK da fórmula 5-20-20 e, em cobertura, foram aplicados $100 \mathrm{~kg} \mathrm{ha}^{-1}$ de nitrogênio $(\mathrm{N})$, na forma de ureia, em duas aplicações de mesma quantidade.

Os animais-teste, em número de três, foram bezerras de corte da raça Angus, com idade e peso médio inicial de oito meses e $154 \pm 4,2 \mathrm{~kg}$, respectivamente. Foram estudados o uso de estações alimentares, o deslocamento, os bocados por estação alimentar e a taxa de bocado de bezerras que foram mantidas exclusivamente em pastagem de azevém (azevém) ou em pastagem de azevém com produto comercial extrusado com gordura como suplemento, na proporção de 0,20\% do peso corporal (gordura) ou grão de milho triturado na proporção de $0,78 \%$ do peso corporal (milho). A quantidade de cada suplemento, em porcentagem do peso corporal, foi ajustada para que estes fossem isolipídicos, e as novilhas ingeriram aproximadamente $0,02 \%$ de extrato etéreo em relação ao peso corporal em ambos os suplementos testados. Os teores de proteína bruta e fibra em detergente neutro foram de 9,2 e $14,6 \%$ e de 12,8 e $29,6 \%$ para milho e gordura, respectivamente. Os suplementos foram fornecidos aos animais diariamente, às 14h. A quantidade fornecida foi ajustada semanalmente, com base na taxa de lotação mantida nos piquetes.

O método de pastejo foi o contínuo, com ajuste de carga para manter a massa de forragem em 1200 e $1500 \mathrm{~kg} \mathrm{ha}^{-1}$ de matéria seca (MS). A utilização da pastagem foi dividida em períodos experimentais de 28 dias. Ao final de cada período, foram realizadas as avaliações do comportamento ingestivo das bezerras.

A massa de forragem (MF; $\mathrm{kg} \mathrm{ha}{ }^{-1} \mathrm{MS}$ ) foi avaliada a cada 14 dias, por meio da técnica de estimativa visual com dupla amostragem. Nas mesmas datas foram realizadas medidas da altura do dossel $(\mathrm{cm})$, com régua graduada de plástico rígido, nos mesmos pontos utilizados para estimativa da MF. A altura do dossel foi considerada como a distância do solo até a altura média do dobramento das folhas.

A forragem proveniente dos cortes foi homogeneizada e dividida em duas subamostras, para determinação do teor de matéria seca e dos componentes botânicos e morfológicos, por meio da separação manual dos componentes: folha de azevém (lâmina), colmo de azevém (bainha da folha + colmo), material morto, inflorescência de azevém e outras espécies. O teor de matéria seca foi determinado por secagem das amostras, em estufa com circulação forçada de ar a $55^{\circ} \mathrm{C}$, por 72 horas. Após a separação botânica e a secagem dos componentes estruturais da pastagem, foi determinada a participação percentual de lâminas foliares, colmos, inflorescências, material morto e outras espécies na massa de forragem. Com base na proporção de folhas e colmos, foi determinada a relação folha:colmo (F:C).

A pesagem dos animais foi realizada a cada 28 dias, com jejum prévio de sólidos e líquidos de 12 horas. Para o cálculo da taxa de lotação (LOT, $\mathrm{kg} \mathrm{ha}{ }^{-1} \mathrm{PC}$ ), foi utilizado o somatório do peso médio dos animais-teste, com o peso médio de cada animal regulador multiplicado pelo número de dias em que eles permaneceram no piquete, dividido pelo número de dias totais do período.

A taxa de acúmulo diário de forragem (TAD, $\mathrm{kg}$ $\mathrm{ha}^{-1}$ MS) foi determinada em três gaiolas de exclusão ao pastejo. A disponibilidade diária de forragem ( $\mathrm{kg} \mathrm{ha}{ }^{-1} \mathrm{dia}^{-1}$ de MS) foi obtida pela soma da TAD com a MF do período, divididas pelo número de dias do período. A oferta de forragem (OF) foi expressa como a disponibilidade de forragem dividida pela carga animal, expressa em $\mathrm{kg}$ de MS de forragem por hectare $\mathrm{kg}^{-1}$ de peso vivo-1 dia (Sollenberg et al., 2005). A oferta de lâminas foliares verdes (OFL) foi obtida por meio da multiplicação da OF pelo percentual de lâminas foliares na MF. Por meio da técnica da simulação de pastejo, foram tomadas amostras de forragem para determinação das características químicas do pasto. Nessas amostras, foi determinado o teor de proteína bruta e fibra em detergente neutro (Robertson e Van Soest, 1981).

As avaliações das estações alimentares e do deslocamento das bezerras foram realizadas durante os períodos de pastejo diurnos, pela manhã e à tarde, em 30/07, 27/08, 24/09 e 22/10. 
Foi observada a atividade de pastejo dos três animais-teste de cada piquete, em cinco ciclos de 10 estações alimentares cada um. Uma estação alimentar foi considerada como o espaço correspondente ao pastejo, sem movimentos das patas dianteiras (Laca et al., 1992), e um passo foi definido como cada movimento das patas dianteiras. Com base nesses dados, foram calculados o número de estações alimentares visitadas por minuto, o tempo de permanência em cada estação alimentar, o número de passos entre cada estação alimentar e o número de passos por minuto (deslocamento).

Foi registrado, com cronômetro, o tempo necessário para os animais realizarem 20 bocados (Hodgson, 1982). A partir desses dados foi calculada a taxa de bocado (boc $\mathrm{min}^{-1}$ ). O número de bocados por estação alimentar (boc est ${ }^{-1}$ ) foi obtido pela divisão da taxa de bocado pelo número de estações alimentares por minuto.

O delineamento experimental foi o inteiramente ao acaso, com medidas repetidas no tempo, com três tratamentos e duas repetições de área. Para o estudo dos padrões de busca e deslocamento, os animais foram considerados as repetições. Os dados foram analisados por meio de análise de variância, comparação de médias e contrastes. Para comparar o efeito dos tratamentos, quando houve diferença, foi utilizado o teste de Tukey, em 5\% de probabilidade. $\mathrm{Na}$ análise de regressão múltipla, para identificar as variáveis independentes com influência sobre a variável resposta, foi utilizado o procedimento Stepwise. Foram obtidas todas as equações possíveis, e uma foi selecionada de acordo com os seguintes critérios: menor valor de $\mathrm{p}$, menor variância residual, maior coeficiente de determinação e menor número de variáveis independentes. Os dados foram submetidos também à análise de regressão em função dos dias de utilização da pastagem. Na análise de regressão, a escolha dos modelos baseou-se na significância dos coeficientes linear, quadrático e cúbico, utilizando-se o teste " $\mathrm{t}$ " de Student, em 5\% de probabilidade $(\mathrm{P})$. As análises foram efetuadas com o auxílio do programa estatístico SAS (2001)

O modelo matemático referente às análises de padrões de busca e deslocamento foi representado por: $\mathrm{Yijk}=\mu+\mathrm{Ti}+\mathrm{Rk}(\mathrm{Ti})+\mathrm{Pj}+$ $(\mathrm{TP}) \mathrm{ij}+$ cijk. Pelo modelo, Yijk representa as variáveis dependentes; $\mu$ é a média de todas as observações; Ti corresponde ao efeito do i-ésimo tratamento; Rk (Ti) é o efeito da k-ésima repetição dentro do i-ésimo tratamento (erro a); $\mathrm{Pj}$ é o efeito do j-ésimo período; (TP)ij representa a interação entre o i-ésimo tratamento e o j-ésimo período; e eijk corresponde ao erro experimental residual (erro b).

\section{RESULTADOS E DISCUSSÃO}

A temperatura média dos meses do desenvolvimento do experimento foi semelhante à média histórica. A precipitação nos meses de julho e outubro foi $21,81 \%(43,4 \mathrm{~mm})$ e $25,15 \%$ $(36,7 \mathrm{~mm})$ inferior à normal pluviométrica, respectivamente, e foi 1,31 vez e 2,4 vezes superior nos meses de agosto e setembro, respectivamente (Tab. 1).

Não houve interação entre as alternativas de suplementos $\times$ períodos de avaliação para as variáveis massa de forragem, altura do pasto, oferta de forragem, oferta de lâminas foliares, massa de folhas, massa de material morto, fibra em detergente neutro (FDN) e proteína bruta (PB) $\quad(\mathrm{P}>0,05) . \quad \mathrm{A}$ massa de forragem $\left(1445,02 \pm 54,27 \mathrm{~kg} \mathrm{ha}^{-1}\right.$ de MS), altura do pasto $(11,67 \pm 1,51 \mathrm{~cm})$, oferta de forragem $(8,92 \pm 0,72 \%$ do PC), oferta de lâminas foliares $(3,77 \pm 0,59 \%$ do PC), massa de folhas $\left(663,16 \pm 67,03 \mathrm{~kg} \mathrm{ha}^{-1}\right.$ de MS), massa de material morto $\left(343,57 \pm 56,76 \mathrm{~kg} \mathrm{ha}^{-1}\right.$ de MS), fibra em detergente neutro $(54,73 \pm 1,47 \%$ da MS) e proteína bruta $(22,46 \pm 1,18 \%$ da MS) foram semelhantes quando as bezerras de corte permaneceram exclusivamente em pastejo ou receberam suplementos. Assim, o manejo semelhante do pasto possibilitou que as bezerras, nas diferentes alternativas de suplementos, fossem mantidas em estrutura semelhante à da pastagem e colhessem teores similares de nutrientes.

Houve interação entre alternativas de suplementos $\times$ datas de avaliação para número de estações visitadas por minuto $(\mathrm{P}=0,0265)$, tempo de permanência em cada estação alimentar $(\mathrm{P}=0,0243)$, número de passos entre estação alimentar $(\mathrm{P}=0,0001)$ e número de passos por minuto ( $\mathrm{P}=0,0042$; Fig. 1).

As bezerras exclusivamente em pastejo e as que receberam grão de milho como suplemento 
visitaram 0,029 e 0,044 estações por minuto a mais (Fig. 1A) e permaneceram, respectivamente, 0,068 e 0,092 segundos a menos em cada estação alimentar (Fig. 1B) a cada dia a mais de pastejo em azevém. Tanto o número de estações alimentares visitadas por minuto (estações por minuto) quanto o tempo de permanência em cada estação alimentar (tempo por estação) foram influenciados pela massa de lâminas foliares (MLF), conforme as equações: estações por minuto azevém $=10,0623$ $0,0053 \mathrm{MLF} ; \mathrm{R}^{2}=0,82 ; \mathrm{P}=0,0021$; estação por minuto milho=10,2012-0,0062MLF; $\mathrm{R}^{2}=0,67$; $\mathrm{P}=0,0126$; tempo por estação azevém $=3,0443+$ $0,0116 \mathrm{MLF} ; \mathrm{R}^{2}=0,86 ; \mathrm{P}=0,0009$; e tempo por estação milho=2,7521+0,0144MLF; $\mathrm{R}^{2}=0,75$; $\mathrm{P}=0,0052$, respectivamente. Esses resultados ratificam a importância da quantidade de lâminas foliares no dossel, no sentido de influenciar a permanência dos animais na estação alimentar (Prache e Rouguet, 1996). A diminuição de $1 \mathrm{~kg}$ de lâminas foliares no dossel forrageiro fez com que as bezerras exclusivamente em pastejo e as que receberam milho visitassem 0,0053 e 0,0062 estações a mais e permanecessem 0,0116 e 0,0144 segundos a menos em cada estação alimentar.

A redução de $0,07 \mathrm{~kg}$ diária na massa de lâminas foliares $\quad\left(\mathrm{MLF}=1158,30-0,07 \mathrm{x} ; \quad \mathrm{R}^{2}=0,91\right.$; $\mathrm{P}<0,0001)$, no decorrer do ciclo fenológico do azevém, motivou as bezerras, que estavam exclusivamente em pastejo e as que receberam milho, a visitarem mais estações e a permanecerem menos tempo em cada estação alimentar. Esse mecanismo é utilizado para otimizar a colheita de forragem e resulta em redução da seletividade do herbívoro (Knegt et al., 2007).

O número de estações alimentares e o tempo de permanência em cada estação alimentar das bezerras que receberam gordura mostraram um comportamento quadrático. As bezerras visitaram o maior número de estações alimentares (7,62 estações por minuto) no $80^{\circ}$ dia de utilização do pasto e permaneceram por menor tempo (8,78 segundos) no $78^{\circ}$ dia de utilização do pasto. O número de estações alimentares visitadas por minuto (estações por minuto) e o tempo de permanência em cada estação alimentar (tempo por estação) das bezerras que receberam gordura foram influenciados pela oferta de forragem (OF), conforme as equações: estação por minuto gordura $=3,0833+0,4008 \mathrm{OF} ; \mathrm{R}^{2}=0,69 ; \mathrm{P}=0,0102$ e tempo por estação gordura=15,9781-0,6365OF; $\mathrm{R}^{2}=0,61 ; \mathrm{P}=0,0212$. $\mathrm{O}$ aumento de $1 \%$ na oferta de forragem fez com que as novilhas visitassem 0,4008 estação a mais e permanecessem 0,6365 segundo a menos em cada estação alimentar. $\mathrm{O}$ recebimento de gordura, então, tornou as bezerras menos dependentes da proporção de lâminas foliares no dossel, pois a oferta de forragem inclui folhas e colmos, e fez com que as bezerras atendessem sua demanda nutricional mais rapidamente, pois os lipídeos são fontes com alta concentração de energia prontamente disponível (Oliveira et al., 2008) e melhoram a eficiência de utilização do nitrogênio da forragem (Poppi e McLennan, 1995).

A oferta de forragem apresentou comportamento cúbico, conforme a equação: $\quad \mathrm{OF}=20,0167$ $0,7398 \mathrm{x}+0,01284 \mathrm{x}^{2}-0,000063 \mathrm{x}^{3} ; \quad \mathrm{R}^{2}=0,66$; $\mathrm{p}=0,0002$. A oferta de forragem foi menor $\left(6,93 \%\right.$ do PC) no $41^{\circ}$ dia e maior $(11,60 \%$ do PC) no $94^{\circ}$ dia de utilização do pasto. Para uma redução linear na oferta de lâminas foliares, o aumento da oferta de forragem, com o decorrer do ciclo, representa também aumento na proporção de colmos no dossel. Essa oferta de forragem é superior ao valor de três vezes o consumo dos animais em pastejo e pode resultar em aumento da senescência e material morto no dossel. Os colmos e o material morto são considerados uma barreira ao pastejo e dificultam o acesso dos animais às folhas (Sollenberger e Burns, 2001), fazendo com que as bezerras aumentem o número de estações alimentares visitadas quando o azevém ingressa no estádio de pré-florescimento (a partir do $56^{\circ}$ dia de sua utilização). Assim, o fornecimento de gordura possibilita menor dependência das bezerras em relação à estrutura do dossel, pois, para uma mudança diária dessa estrutura, as bezerras que recebem gordura mudam seu comportamento, nas estações alimentares, mais tardiamente que as demais bezerras.

O número de passos entre estação alimentar, das bezerras exclusivamente em pastejo, teve um comportamento quadrático. As bezerras realizaram menor número de passos entre estação alimentar (1,48 passos) no $75^{\circ}$ dia de utilização da pastagem. O número de passos entre estação alimentar (passos entre estação) das bezerras em pastejo foi influenciado pela altura do dossel 
(ALT), conforme a equação: passos entre estação azevém=0,3954+0,1559ALT; $\mathrm{R}^{2}=0,52$; $\mathrm{P}=0,0453$. A altura comportou-se de forma quadrática, conforme a equação: $\mathrm{ALT}=25,70$ $0,499 x+0,0035 x^{2} ; R^{2}=0,82 ; P<0,0001$. A menor altura $(7,91 \mathrm{~cm})$ foi encontrada no $71^{\circ}$ dia de utilização do pasto. $\mathrm{O}$ aumento de $1 \mathrm{~cm}$ na altura do dossel fez com que as novilhas aumentassem 0,1497 passo entre estação alimentar. O deslocamento dos animais entre estação alimentar é reflexo da massa de bocado colhida no último bocado da estação alimentar anterior. $\mathrm{O}$ aumento na altura do dossel possibilita que o animal colha maior massa de bocado e permite que ele caminhe mais antes de eleger uma nova estação alimentar enquanto mastiga o último bocado (Carvalho e Moraes, 2005). Essa estratégia permite ao animal avaliar melhor o ambiente alimentar disponível, despendendo, assim, mais tempo para a procura de sítios de pastejo preferidos (Roguet et al., 1998).

O número de passos entre cada estação alimentar das bezerras que receberam milho comportou-se de forma cúbica. Elas realizaram maior número de passos entre cada estação alimentar $(3,99$ passos) no $44^{\circ}$ dia e menor ( 0,80 passo) no $97^{\circ}$ dia de utilização da pastagem. Essa variável foi explicada pela oferta de forragem (OF), conforme a equação: passos entre estação milho=8,55-0,76OF; $\quad \mathrm{R}^{2}=76 ; \quad \mathrm{P}=0,0047$. O aumento de $1 \%$ na oferta de forragem fez com que estas novilhas diminuíssem 0,76 passo entre estação alimentar. O deslocamento entre cada estação alimentar está ligado à proporção de lâminas foliares, no decorrer do ciclo, em cada oferta de forragem. Conforme Heringer e Carvalho (2002), a oferta de forragem não quantifica os componentes estruturais do pasto, e a mesma oferta de forragem, com o avanço do ciclo fenológico, possui variação na sua composição. A menor oferta de forragem, no estádio vegetativo do azevém (que corresponde do primeiro ao $56^{\circ}$ dia de utilização da pastagem), apresentou maior quantidade de lâminas foliares $(79,53 \%$ da composição estrutural da massa de forragem); assim, bezerras realizaram maior deslocamento até o encontro de uma nova estação alimentar.
O número de passos por minuto (deslocamento) das novilhas exclusivamente em pastejo comportou-se de forma quadrática (Fig. 1). O menor deslocamento (9,82 passos por minuto) foi no $64^{\circ}$ dia de utilização da pastagem. O deslocamento foi influenciado pela massa de forragem $\left(\mathrm{MF} ; \mathrm{r}^{2}=0,61\right)$ e pelo teor de fibra em detergente neutro do pasto $\left(r^{2}=0,22\right)$, conforme a equação: deslocamento azevém $=22,0711+$ $0,316 \mathrm{MF}-0,974 \mathrm{FDN} ; \mathrm{R}^{2}=0,83 ; \mathrm{P}=0,0468$.

A massa de forragem (MF) variou de forma quadrática, conforme a equação: $\mathrm{MF}=1399,775$ $8,245 \mathrm{x}-0,106 \mathrm{x}^{2} ; \mathrm{R}^{2}=0,83 ; \mathrm{P}=0,0011$. A menor massa de forragem $\left(1241,98 \mathrm{~kg} \mathrm{ha}^{-1}\right.$ de MS) ocorreu no $34^{\circ}$ dia de utilização da pastagem. O aumento de $0,316 \mathrm{~kg}$ de matéria seca na massa de forragem fez com que as novilhas aumentassem 0,316 passo por minuto, a partir da massa de forragem de $1306,21 \mathrm{~kg} \mathrm{ha}^{-1}$ de MS, quando mantido constante o teor de fibra em detergente neutro. Conforme Bailey et al. (1996), o animal desloca-se visando encontrar locais com maior disponibilidade de forragem e maior riqueza de nutrientes.

O teor de fibra em detergente neutro (FDN) variou de forma linear crescente, conforme a equação: $\quad \mathrm{FDN}=48,203+0,093 \mathrm{x} ; \quad \mathrm{R}^{2}=0,80$; $\mathrm{P}<0,0001$. O aumento de $0,093 \%$ diário na matéria seca de FDN, no decorrer do ciclo fenológico do azevém, motivou as bezerras, que estavam exclusivamente em pastejo, a realizarem 0,974 passo a menos por minuto, até o pasto consumido, obtido por simulação de pastejo, atingir teor de FDN de $54,15 \%$ da MS, quando mantida constante a massa de forragem.

O número de passos entre estação alimentar e por minuto das bezerras que receberam gordura não se adequou a nenhum modelo de regressão. $\mathrm{O}$ deslocamento das bezerras que receberam milho comportou-se de forma cúbica. Elas realizaram maior deslocamento (17,01 passos por minuto) no $46^{\circ}$ dia e menor (12,06 passos por minuto) no $87^{\circ}$ dia de utilização da pastagem. 

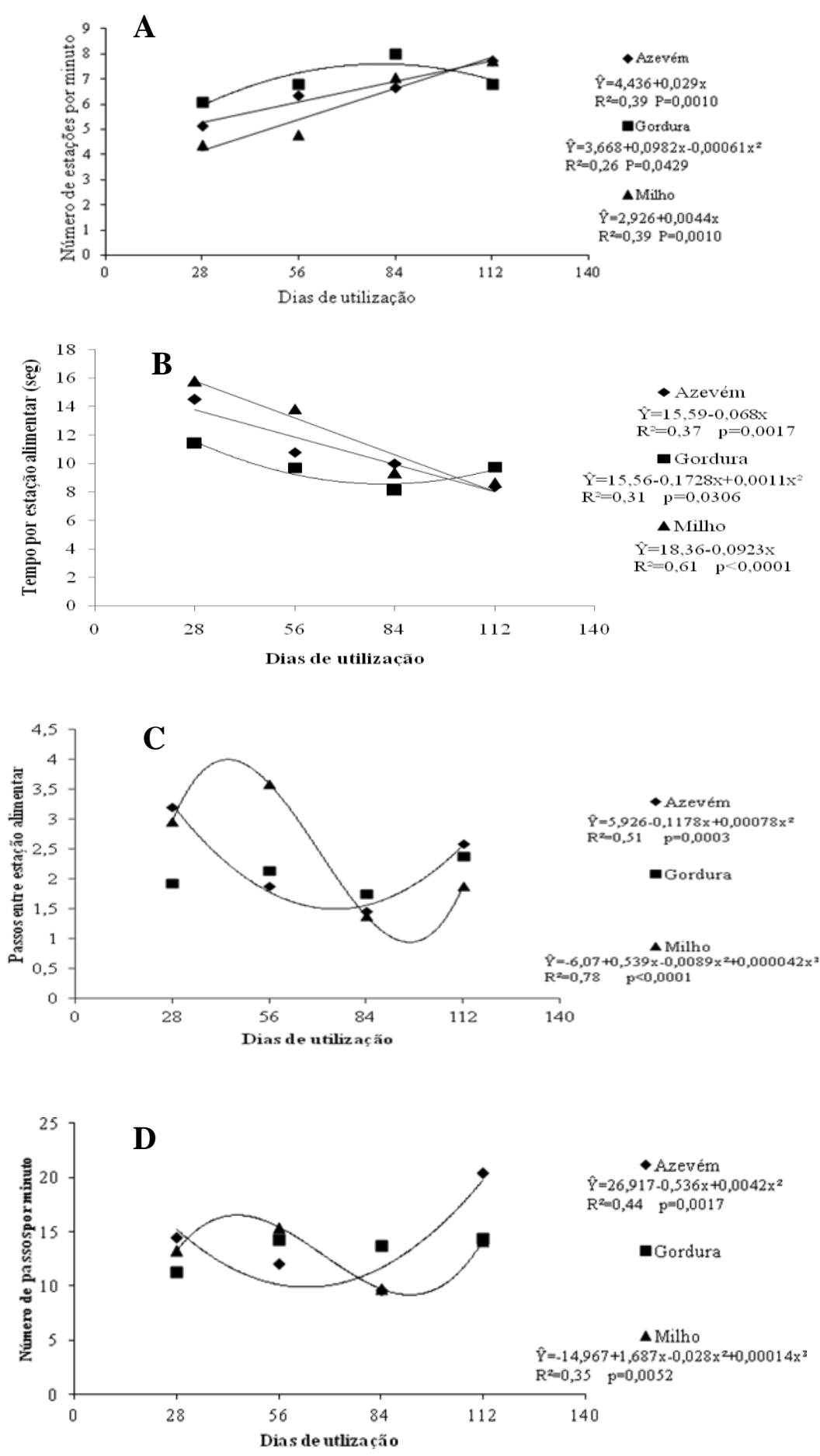

Figura 1. Número de estações alimentares por minuto (A), tempo por estação alimentar (B), número de passos entre estação alimentar (C) e número de passos por minuto (D) de bezerras de corte em pastagem exclusiva de azevém (azevém), que receberam grão de milho como suplemento (milho) e produto comercial extrusado como gordura (gordura). 
O número de bocados por estação alimentar foi semelhante $(p=0,1093)$ para as bezerras que receberam diferentes alternativas de suplemento, com média de 7,53 bocados por estação alimentar. Essa taxa de bocado por estação alimentar está associada com a estrutura da vegetação em cada estação alimentar (Carvalho et al., 2001), e a manutenção da estrutura da pastagem semelhante fez com que os animais realizassem número de bocados similar por estação alimentar. Houve interação entre as alternativas de suplemento $\times$ as datas de avaliação para taxa de bocado $(\mathrm{P}<0,0001)$.

A taxa de bocado das bezerras exclusivamente em pastejo comportou-se de forma quadrática ( $\left.\hat{Y}=16,4000+0,9559 \mathrm{x}-0,0058 \mathrm{x}^{2} ; \mathrm{R}^{2}=0,78 ; \mathrm{P}<0,0001\right)$. As bezerras realizaram maior número de bocados por minuto ( 56 bocados) no $82^{\circ}$ dia de utilização do azevém, correspondente ao final do segundo período de avaliação do pasto (estádio de préflorescimento). A taxa de bocado foi influenciada pela altura do dossel (ALT), conforme a equação: bocado azevém $=66,59$ $1,45 \mathrm{ALT} ; \mathrm{R}^{2}=0,50 ; \mathrm{P}=0,0487$. O aumento de $1 \mathrm{~cm}$ na altura do dossel fez com que as bezerras reduzissem 1,45 bocado por minuto. A altura do dossel tem reflexo importante sobre a acessibilidade da forragem pelos animais, pois, em pastagens de clima temperado, alturas inferiores a $8,32 \mathrm{~cm}$, podem dificultar a apreensão, principalmente por bovinos que utilizam a língua para apreender forragem, fazendo com que as bezerras aumentem a taxa de bocado. O aumento na altura do dossel, de 8,32 para $13,72 \mathrm{~cm}$, pode ter proporcionado maior profundidade do bocado, a partir do $82^{\circ}$ dia de utilização do azevém, e com isso as bezerras diminuíram o número de bocados realizados por minuto.

A taxa de bocado das bezerras que receberam gordura comportou-se de forma cúbica $\left(\hat{Y}=-24,41667+4,07788 x-0,06334 x^{2}+0,00028 x^{3}\right.$; $\left.\mathrm{R}^{2}=0,81 ; \quad \mathrm{P}<0,0001\right)$. As bezerras realizaram maior número de bocados por minuto $(57,11$ bocados) no $46^{\circ}$ dia (estádio vegetativo) e menor taxa de bocado $(33,24$ bocados $)$ no $104^{\circ}$ dia (estádio de florescimento) de utilização do azevém. Para essas bezerras, a taxa de bocado (bocado) foi influenciada pela massa de forragem $\left(\mathrm{MF} ; \mathrm{r}^{2}=0,63\right)$ e pela oferta de lâminas foliares (OLF; $\left.\mathrm{r}^{2}=0,22\right)$, conforme a equação: bocado gordura=114,1363-0,0409MF-2,2934OLF;
$\mathrm{R}^{2}=0,85 ; \mathrm{P}=0,0462$. O aumento gradativo da massa de forragem de $1246,41 \mathrm{~kg} \mathrm{ha}^{-1}$ de MS, no estádio vegetativo $\left(47^{\circ}\right.$ dia de utilização do azevém), para $1688,79 \mathrm{~kg} \mathrm{ha}^{-1}$ de MS, no estádio de florescimento do azevém $\left(104^{\circ}\right.$ dia de utilização do azevém), proporcionou adequada oferta de lâminas foliares, acarretando diminuição da taxa de bocado desses animais. A partir do $104^{\circ}$ dia de utilização do pasto, mesmo com o aumento da massa de forragem, a diminuição da oferta de lâminas foliares, inferiores a 1,54\% do PC de lâminas foliares, resultou em aumento na taxa de bocado.

A taxa de bocado das bezerras que receberam milho comportou-se de forma quadrática ( $\hat{Y}=25,8500+0,4831 \mathrm{x}-0,0028 \mathrm{x}^{2} ; \mathrm{R}^{2}=0,63 ; \mathrm{P}=0,0013$ ). As bezerras realizaram maior número de bocados (47 bocados) no $86^{\circ}$ dia de utilização do azevém, correspondente ao início do terceiro período de avaliação do pasto (estádio de florescimento). A taxa de bocado (bocado) foi influenciada pela relação folha:colmo (RFC), conforme a equação: bocado milho=48,264-2,330RFC; $\mathrm{R}^{2}=0,73$; $\mathrm{P}=0,0070$. Em cada estádio fenológico, as forrageiras apresentam diferentes proporções de folhas e colmos no perfil do pasto (Carvalho et al., 2001), modificando a acessibilidade da forragem a ser consumida. Houve interação entre as alternativas de suplemento $\times$ as datas de avaliação para a relação folha:colmo $(\mathrm{P}=0,0058)$, e esta apresentou comportamento linear decrescente quando as bezerras receberam milho, conforme a equação: RFC milho=5,292-0,044x; $\mathrm{R}^{2}=0,90 ; \mathrm{P}=0,0004$. A diminuição de um (1) ponto na relação folha:colmo fez com que as bezerras aumentassem 2,33 bocados por minuto, até a relação folha:colmo atingir 1,5 , a partir do $86^{\circ}$ dia de utilização do azevém; mesmo com a diminuição da relação folha:colmo, estas bezerras acabam diminuindo a taxa de bocado, $o$ que pode ser explicado pelo maior tempo na seleção de cada bocado.

\section{CONCLUSÕES}

Os modelos de predição para as variáveis tempo por estação alimentar, número de estações alimentares por minuto, número de passos entre estação alimentar, número de passos por minuto e taxa de bocado de bezerras de corte diferem conforme o tipo de suplemento. $\mathrm{O}$ uso de estações alimentares (tempo por estação alimentar e número de estações alimentares por 
minuto) por bezerras que recebem produto comercial extrusado com gordura é menos dependente da proporção de lâminas foliares no dossel. O deslocamento (passos entre estações e passos por minuto) de bezerras exclusivamente em pastejo e que recebem grão de milho é influenciado pela estrutura do pasto. $\mathrm{O}$ número de bocados em cada estação alimentar não é influenciado pelo fornecimento de suplemento. A taxa de bocado dos animais suplementados com grão de milho e produto comercial extrusado com gordura é influenciada pela proporção de lâminas foliares no dossel.

\section{REFERÊNCIAS}

BAILEY, D.M.; GORSS, J.E.; LACA, E.A. et al. Mechanisms that result in large herbivore grazing distribution patterns. J. Range Manag., v.49, p.386400, 1996.

CARVALHO, P.C.F; MELIZZARA, J.C.; FONSECA, L. et al. Do bocado ao sítio de pastejo: manejo em 3D para compatibilizar a estrutura do pasto e o processo de pastejo. In: SIMPOSIO DE FORRAGICULTURA E PASTAGEM, v.7, 2009. Lavras. Anais.... Lavras: UFLA, v.1, p.116-137, 2009.

CARVALHO, P.C.F; MORAES, A. Comportamento ingestivo de ruminantes: bases para o manejo sustentável do pasto. In: CECATO, U.; JOBIM, C.C. (Org.) Manejo sustentável em pastagem. Maringá: UEM, v.1, p.1-20, 2005.

CARVALHO, P.C.F.; RIBEIRO FILHO, H.M.N.; POLI, C.H.E.C. et al. Importância da estrutura da pastagem na ingestão e seleção de dietas pelo animal em pastejo. In: XXXVIII REUNIÃO ANUAL DA SOCIEDADE BRASILEIRA DE ZOOTECNIA. Piracicaba, Anais... Piracicaba. v.1, p.853-871, 2001.

GLIENKE, C.L.; ROCHA, M.G.; ROSO, D. et al. Ingestive behavior and displacement patterns of beef heifers on Italian ryegrass pasture. Rev. Bras. Zootec., v.39, p.247-254, 2010.

HERINGER, I.; CARVALHO, P.C.F. Ajuste da carga animal em experimentos de pastejo: uma nova proposta. Cienc. Rural, v.32, p.675-679, 2002.

HODGSON, J. Ingestive behavior. In: LEAVER, J.D. (Ed.) Herbage intake handbook. Hurley: British Grassland Society, 1982. p.113.
KNEGT, H.J.; HENGEVEL, G.M.; VAN LANGEVELD, F. et al. Patch density determines movement patterns and foraging efficiency of large herbivores. Behav. Ecol., v. 18, p.1065-1072, 2007.

LACA, E.A.; UNGAR, E.D.; SELIGMAN, N. Effects of sward height and bulk density on bite dimensions of cattle grazing homogeneous sward. Grass and Forage Sci., v.47, p.91-102, 1992.

LIN, H.; BOYSLON, T.D.; CHANG, M.J. et al. Survey of the conjugated linoleic acid contents of dairy productions. J. Dairy Sci., v.78, p.2358-2365, 1995.

OLIVEIRA, R.L.; BAGALDO, A.R.; LADEIRA, M.M. et al. Desempenho produtivo e custos com alimentação de búfalas lactantes submetidas a dietas com diferentes fontes de lipídeo. Rev. Bras. Zootec., v.37, p.1503-1508, 2008.

POPPI, D.P; McLENNAN, S.R. Protein and energy utilization by ruminants at pasture. J. Anim. Sci., v.73, p.278-290, 1995.

PRACHE, S.; ROGUET, C. Influence de la structure $\mathrm{du}$ couvert sur le comportement d'ingestion. Clermont-Ferrand: Institut National de la Recherche Agronomique, 1996. p.22-24.

ROBERTSON, J.B.; VAN SOEST, P J. The detergent system of analysis. In: JAMES, W.P.T.; THEANDER, $\mathrm{O}$. (Eds.), The analysis of dietary fibre in food. New York: Marcel Dkker, Chapter 9, 1981. p.123-158

ROGUET, C.; DUMONT, B.; PRACHE, S. Selection and use of feeding sites and feeding stations by herbivores: A review. Ann. Zootech. v.47, p.225-244, 1998.

SANTOS, D.T.; ROCHA, M.G.; QUADROS, F.L.F. Suplementos energéticos para recria de novilhas de corte em pastagens anuais. Desempenho animal. Rev. Bras. Zootec., v.34, p.209-219, 2005.

SOLLENBERGER, L.E.; BURNS, J.C. Canopy characteristics, ingestive behavior and herbage intake in cultivated tropical grasslands. In: INTERNATIONAL GRASSLAND CONGRESS, 19, 2001, São Pedro. Proceedings... Piracicaba: Fealq. p.321-327, 2001.

STATISTICAL ANALYSES SYSTEM - SAS. Statistical analysis user's guide. Version 8.2. Cary: SAS Institute, 2001. 1686p. 